\title{
Comparison of Three Different Epidural Solutions in Cardiac Surgery for Stress Protection
}

\author{
Jean-François Olivier ${ }^{1}$, Ignatio Prieto ${ }^{2}$, Fadi Basile ${ }^{2}$ and Thomas Hemmerling ${ }^{*}, 1$ \\ ${ }^{I}$ PeriCARG (Perioperative Cardiac Research Group), Department of Anesthesiology, McGill University, Montréal, \\ Québec, Canada \\ ${ }^{2}$ Department of Cardiac Surgery, Hôtel-Dieu, Centre Hospitalier de l'Université de Montréal, Canada
}

\begin{abstract}
Background: Different solutions are possible for thoracic epidural analgesia in cardiac surgery. So far, local anesthetics alone or in combination with either clonidine or opioids have been used.

Aims: To determine the stress protection provided by different epidural solutions throughout cardiac surgery.

Study Design: A randomized, prospective, double blind study in patients undergoing off-pump coronary artery bypass grafting (OPCAB), randomized in three different groups. Thoracic epidural analgesia was installed more than $1 \mathrm{~h}$ before application of heparin at levels of T2 to T4; analgesia was provided by $8 \mathrm{ml}$ of bupivacaine $0.25 \% 15$ min prior to surgery and extubation, and $10 \mathrm{ml} / \mathrm{h}$ during and up to $72 \mathrm{~h}$ after surgery using one of the following regimens: bupivacaine $0.125 \%$ solely, bupivacaine $0.125 \%$ with fentanyl $3 \mu \mathrm{g} / \mathrm{mL}$ or bupivacaine $0.125 \%$ with clonidine $0.6 \mu \mathrm{g} / \mathrm{mL}$. Patients were blockrandomized for one of the three treatments. Cortisol and glucose values were determined before surgery, at extubation and $1 \mathrm{~h}$ and $3 \mathrm{~h}$ after surgery. Pain scores were assessed up to $48 \mathrm{~h}$ after surgery. Hemodynamic stability was also recorded in form of heart rate, systolic and diastolic blood pressure. Multi-comparison ANOVA and Chi-square test were used to compare the data, presented as mean (SD) or median $\left(25^{\text {th }}\right.$ and $75^{\text {th }}$ percentile), $\mathrm{P}<0.05$.
\end{abstract}

Study Setting: A cardiac surgery unit at a tertiary university hospital.

Participants: Forty-two patients undergoing OPCAB were enrolled.

Main Results: All patient data as well hemodynamic stability were not different between the three groups. All patients were successfully extubated in theatre immediately after surgery. Pain control was good and not significantly different between the groups. Mean glucose concentrations \pm SD before surgery and (significantly higher) $3 \mathrm{~h}$ after surgery were $5.4 \pm$ $1.0 \mathrm{mmol} \mathrm{l}^{-1}$ and $8.4 \pm 1.6 \mathrm{mmol} \mathrm{l}^{-1}$ for bupivacaine alone, $5.2 \pm 0.5 \mathrm{mmol} \mathrm{l}^{-1}$ and $8.5 \pm 2.2 \mathrm{mmol} \mathrm{l}^{-1}$ for bupivacaine plus fentanyl and $5.5 \pm 1.6 \mathrm{mmol}^{-1}$ and $9.5 \pm 2.1 \mathrm{mmol} \mathrm{l}^{-1}$ for bupivacaine and clonidine, respectively. The mean cortisol values $\pm \mathrm{SD}$ in the pre-operative period and $3 \mathrm{~h}$ after surgery were $413 \pm 162 \mathrm{nmol}^{-1}$ and $562 \pm 173 \mathrm{nmol}^{-1}$ for bupivacaine alone, $393 \pm 107 \mathrm{nmol} \mathrm{l}^{-1}$ and $581 \pm 265 \mathrm{nmol} \mathrm{l}^{-1}$ for bupivacaine and fentanyl and $409 \pm 159 \mathrm{nmol} \mathrm{l^{-1 }}$ and $570 \pm 160 \mathrm{nmol}$ $1^{-1}$ for bupivacaine and clonidine, respectively. There were no significant differences between the groups.

Conclusions: We conclude that short-term stress protection with TEA is equally effective with solely bupivacaine, bupivacaine with fentanyl or clonidine.

Keywords: OPCAB, TEA, stress protection.

\section{INTRODUCTION}

Thoracic epidural analgesia (TEA) has been advantageous in providing superior analgesia and better respiratory function in comparison to opioid based techniques in different types of surgery [1]. Because of these advantages, TEA has gained popularity in cardiac surgery despite the possible risks of epidural hematoma formation. Some studies showed particular advantages of epidural analgesia in cardiac surgery: TEA provides good hemodynamic control [2,3],

*Address correspondence to this author at the Department of Anesthesiology, Montreal General Hospital, 1650 Cedar Avenue, Montreal, H3G 1B7, Canada; Tel: 514-934-1934, Ext. 43677; Fax: 514-934-8249;

E-mail: thomashemmerling@hotmail.com allows early extubation times $[3,4]$ with better pulmonary function and very little postoperative pain [5]. Thoracic epidural analgesia also reduces morbidity by reducing respiratory complications like atelectasis and pneumonia and possibly supraventricular arrhythmias [6].

Cardiac surgery like any type of surgery triggers an inflammatory reaction. The stress response initiates a catabolic state reflected by muscle breakdown, hyperglycemia [7-9], altered substrate utilization [10] and altered immune function [11]. The cytokine response may also promote end organ dysfunction and may have an impact on cardiac surgery outcome [12-14].

If it is true that TEA with a sole local anesthetic agent reduces the stress response after cardiac surgery, it would be 
interesting to see whether the addition of clonidine or opioid- in our case: fentanyl - could add further to the efficacy to reduce the inflammatory process after cardiac surgery.

In this study, we investigated three different epidural solutions assuming that the addition of either clonidine or fentanyl to bupivacaine might improve the stress protection compared to bupivacaine solution alone.

\section{METHODS}

This is a randomized double-blind controlled trial. Institutional and review board approved this investigation. Fortytwo consenting patients undergoing off-pump coronary artery bypass $(\mathrm{OPCAB})$ grafts by two surgeons were included and randomized to receive one of three epidural solutions. Those three epidural groups were:

- $\quad$ Bupivacaine $0,125 \%$ alone (B)

- $\quad$ Bupivacaine $0,125 \%$ and clonidine $0,06 \%$ (BC)

- $\quad$ Bupivacaine $0,125 \%$ and fentany $13 \mu \mathrm{g} / \mathrm{ml}$ (BF)

Before surgery, patients were familiarized with the insertion of the thoracic epidural catheter and ultra-fast-track protocol (immediate extubation in the operating room). All patients consented for the insertion of the epidural catheter immediately before surgery and immediate extubation after the surgery.

We included patients aged between 18 and 90 and having an ejection fraction of at least $30 \%$. Exclusion criteria were patient refusal to participate in the study or use of epidural analgesia, pregnant women, patients with contraindication for the installation of the epidural catheter such as site infection or coagulopathy. We also excluded diabetic patients.

Routine monitoring included 5-lead electrocardiography, invasive blood pressure monitoring via femoral artery catheter, central venous pressure monitoring via right subclavian venous catheter, pulse oximetry and BIS monitoring (A-2000 Bispectral Index monitoring system, Aspect Medical System, MN, USA). Anesthesia was performed in the same fashion for all patients: At arrival in the operating theatre, an epidural catheter was inserted at T2-T4 under local anesthesia. Verification of correct placement was performed using 2-3 $\mathrm{ml}$ of lidocaine 1,5\% with epinephrine 1:200000. Correct functioning of the catheters were tested with ice.

Anesthesia was then induced by fentanyl $3 \mu \mathrm{g} / \mathrm{kg}$, followed by propofol 1-2 $\mathrm{mg} / \mathrm{kg}$. After mask ventilation using $100 \%$ oxygen for $3 \mathrm{~min}$, endotracheal intubation was facilitated by rocuronium $0.6 \mathrm{mg} / \mathrm{kg}$. After the trachea was intubated, a right sub-clavian central venous catheter and a right femoral artery catheter were inserted.

Intraoperative anesthesia was maintained by sevoflurane titrated to maintain a BIS around 50, analgesia by epidural analgesia according to group assignment in a blinded way.

In all groups, a bolus of $4-8 \mathrm{ml}$ of bupivacaine $0.25 \%$ was given $15 \mathrm{~min}$ before skin incision and $20 \mathrm{~min}$ before extubation in the operating theatre. The solutions under study were started after the initial bolus of bupivacaine and kept for three days after the surgery at a rate of $10 \mathrm{ml} / \mathrm{h}$. Active temperature control was achieved with forced air warming therapy and increased room temperature $\left(22^{\circ} \mathrm{C}\right.$ or more). Forced air warming therapy was ascertained by using two BAIR Huggers (Augustine medical company, Eden Prairie, MN, USA). The first one was attached to a modified plastic cover to provide warm air around the patient's head and was started immediately after induction of anesthesia. The second one was attached to a sterile lower body cardiac warming blanket (Augustine medical company, Eden Prairie, MN, USA, Model 630 cardiac blanket) applied after saphenous vein harvesting.

During the ischemic period, treatable bradycardia was defined as a heart rate lower than $40 \mathrm{~min}^{-1}$ and was treated with increment doses of iv ephedrine $5 \mathrm{mg}$. Hypotension was defined as a systolic blood pressure inferior to $70 \mathrm{~mm} \mathrm{Hg}$ and was treated with increments of iv phenylephrine $50 \mu \mathrm{g}$. Heparin $150 \mathrm{IU} / \mathrm{kg}$ was given 5 minutes prior to ischemia for all patients and at least one hour after epidural catheter placement.

Extubation criteria were: a cooperative and alert patient; recovery of neuromuscular function assessed by train-of-four (TOF) $>0.8$ at the adductor pollicis muscle, pulse oxymetry superior to $96 \%$, $\mathrm{P}_{\mathrm{ETCO} 2}$ less than $45 \mathrm{~mm} \mathrm{Hg}$, stable hemodynamics and bladder temperature superior to $35^{\circ} \mathrm{C}$. Temporary pacing, intra aortic balloon pump assist or vasopressive medications were not considered to be a contraindication to extubation as long as blood pressure remained stable.

After extubation in the operating room, the patients were transferred to the post-anesthesia care unit (PACU) for a short-term stay of $2 \mathrm{~h}$ followed by overnight treatment in the ICU.

We recorded patient demographics data, pre-operative medical status, current medications, left ventricular function as well as operative data (number of grafts, time of ischemia, hemodynamic data), any surgical complications and time to extubation.

Glucose and cortisol levels were measured immediately after installation of the femoral artery catheter (immediately after intubation), immediately after extubation, at $1 \mathrm{~h}$ and $3 \mathrm{~h}$ after surgery.

Each blood sample was immediately transferred to a heparinized tube and centrifuged at $4^{\circ} \mathrm{C}$ (at $3000 \mathrm{rpm}$ for 15 minutes). The obtained supernatant was stored at $-70^{\circ} \mathrm{C}$ until analysis. Plasma glucose levels were measured using a glucose analyzer (model GM7; Analox Instruments Ltd UK, London, England). Plasma cortisol concentrations were analyzed using double-antibody radioimmunoassay (Amersham International, Bucks, England).

Pain intensity was measured by a numeric pain score at rest $(0=$ no pain, $10=$ worst pain imaginable $)$ and recorded $2 \mathrm{~h}, 6 \mathrm{~h}, 24 \mathrm{~h}$ and $48 \mathrm{~h}$ after surgery. Post-operative blood pressure and heart rate were documented continuously for the first 6 hours after surgery. Complications such as bleeding, hemodynamic problems, arrhythmias and respiratory dysfunctions (with arterial $\mathrm{PO}_{2}$ and $\mathrm{PCO}_{2}$ for the first 12 hours) were also noted. Side effects such as drowsiness, nausea, pruritus, paresthesia as well as neurological symptoms such as unexplained muscle weakness in the legs or arm were noted and led to discontinuation of TEA, followed by neurological investigations. 
Data are presented as mean and standard deviation and median $\left(25^{\text {th }}, 75^{\text {th }}\right.$ percentile, min, max) for glucose and cortisol. Comparison of all continuous data was performed between the three groups using multi-comparison ANOVA and of all categorical data using Chi-square test, $\mathrm{P}<0.05$ was considered to show significant difference. Since this was a pilot study, no Power calculation was performed prior to the study.

\section{RESULTS}

Baseline characteristics are shown in Table 1. There were no significant differences between the three groups for age, sex, weight, ejection fraction, number of grafts and ischemic time (Table 1). The incidence of past myocardial infarction or stroke, hypertension, diabetes, chronic obstructive pulmonary disease and renal insufficiency was also similar. Room temperature, body temperature at the beginning of the surgery and at the moment of extubation was not different. Thoracic epidural catheter insertion was successful in all patients. There was no difference between groups for the incidence of nausea or vomiting. All patients experienced good analgesia after surgery with pain scores below 4 in the vast majority of patients (Table 2). There were no differences between the three groups. None of the patients required supplementary analgesia for leg pain. The incidence of paresthesia in dermatoma higher than T1 was not different between the three groups. There was no patient with any drowsiness or reduced vigilance due to any of the three solutions. Blood pressure and heart rate remained stable throughout surgery by using phenylephrine in 12 patients in the bupivacaine and clonidine and bupivacaine and fentanyl group, respectively, and in 9 patients in the bupivacaine group. This was not different between the groups.
Glucose concentrations before surgery and (significantly higher, $\mathrm{P}<0.01) 3 \mathrm{~h}$ after surgery were $5.4 \pm 1.0$ and $8.4 \pm$ 1.6 for bupivacaine alone, $5.2 \pm 0.5$ and $8.5 \pm 2.2$ for bupivacaine plus fentanyl and $5.5 \pm 1.6$ and $9.5 \pm 2.1$ for bupivacaine and clonidine, respectively (Fig. 1). These values were not statistically significant between the groups.

The cortisol values in the pre-operative period and $3 \mathrm{~h}$ after surgery were $413 \pm 162$ and $562 \pm 173$ for bupivacaine alone, $393 \pm 107$ and $581 \pm 265$ for bupivacaine and fentanyl and $409 \pm 159$ and $570 \pm 160$ for bupivacaine and clonidine, respectively without significant differences throughout the measurement period or between the groups (Fig. 2).

\section{DISCUSSION}

Our findings show that the addition of clonidine or fentanyl does not create better stress protection than the sole use of bupivacaine for TEA in OPCAB. All three solutions provided equal stress protection with moderate increases in blood glucose and circulating cortisol concentration. Regardless of the type of epidural analgesia all patients were extubated in the operating room and showed good postoperative pain control. There was no drowsiness or nausea and vomiting associated with any of the three solutions.

\section{Inflammatory and Catabolic Responses, TEA and Out- come in Cardiac Surgery}

Hyperglycemia is a prominent feature of the metabolic alterations induced by surgical tissue trauma. During cardiac surgery the disturbance of glucose homeostasis is particularly severe with blood glucose values frequently exceeding $15 \mathrm{mmol} / \mathrm{L}$ in non-diabetic $[15,16]$ and $20 \mathrm{mmol} / \mathrm{L}$ in dia-

\section{Table 1. Demographic Data}

\begin{tabular}{|c|c|c|c|}
\hline & Bupivacaine $0.125 \%$ & Bupi + Fentanyl $3 \mu \mathrm{g} / \mathrm{ml}$ & Bupi + Clonidine $0.6 \mu \mathrm{g} / \mathrm{ml}$ \\
\hline Age (y) & $65(7)$ & $66(11)$ & $66(8)$ \\
\hline Weight (kg) & $72(15)$ & $77(13)$ & $72(15)$ \\
\hline $\operatorname{Sex}(m / f)$ & $11 / 3$ & $9 / 5$ & $9 / 5$ \\
\hline Ejection fraction (\%) & $63(9)$ & $65(11)$ & $55(11)$ \\
\hline Operative time (min) & $105(30)$ & $114(14)$ & $112(36)$ \\
\hline Number of grafts & $3(1)$ & $3(1)$ & $3(1)$ \\
\hline Ischemic time (min) & $17(7)$ & $17(6)$ & $17(5)$ \\
\hline $\mathrm{PO}_{2}(\mathrm{mmHg})$ & $189(60)$ & $138(65)$ & $142(53)$ \\
\hline $\mathrm{PCO}_{2}(\mathrm{mmHg})$ & $47(4)$ & $48(4)$ & $45(4)$ \\
\hline
\end{tabular}

Table 2. Pain Scores at Forced Inspiration/Expiration

\begin{tabular}{|c|c|c|c|}
\hline Pain Score (0-10) & Bupivacaine & Bupi + Fentanyl & Bupi+ Clonidine \\
\hline \hline 0h po. & $1.5(2.4)$ & $0.8(2.4)$ & $1.1(2.3)$ \\
\hline 2h po. & $1.7(1.4)$ & $0.6(1.5)$ & $0.8(1.5)$ \\
\hline 6h po. & $1.1(1)$ & $0.3(0.9)$ & $0.2(0.6)$ \\
\hline 24h po. & $0.9(1)$ & $0.6(1)$ & $0.1(0.3)$ \\
\hline 48h po. & $0.6(0.9)$ & $0.2(0.6)$ & $0.3(0.7)$ \\
\hline
\end{tabular}




\section{Glucose Levels}

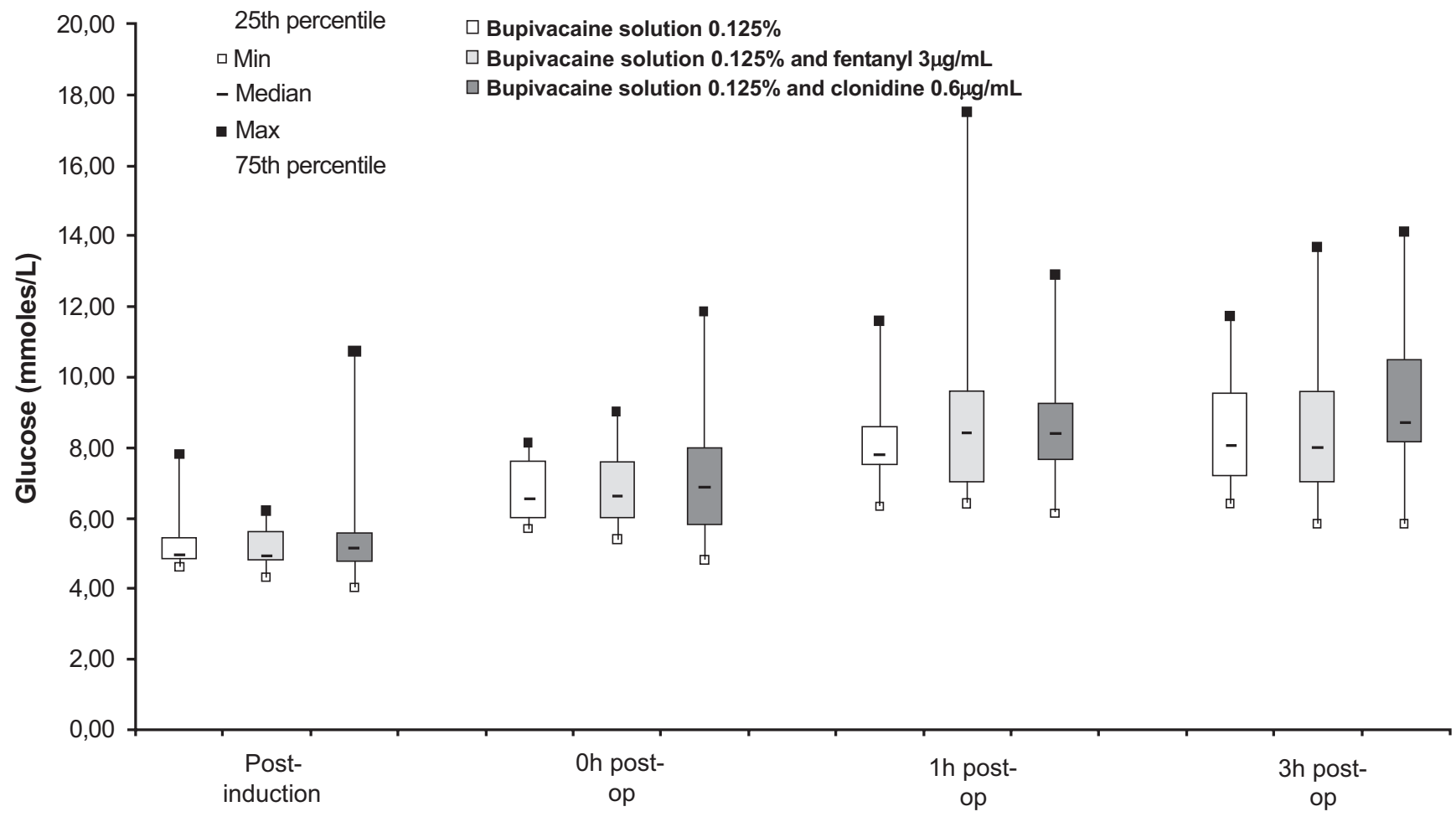

Fig. (1). Glucose levels immediately after intubation, immediately after extubation and $1 \mathrm{~h}$ and $3 \mathrm{~h}$ after surgery.

betic subjects [17].

Perioperative hyperglycemia has been demonstrated to be an independent risk predictor after cardiac operations. For each $1 \mathrm{mmol} / \mathrm{L}$ increase of blood glucose above $6.1 \mathrm{mmol} / \mathrm{L}$ the risk of adverse outcome increased by $17 \%$ in diabetic patients undergoing cardiac surgery [18].

Tight glycemic control attenuated the systemic inflammatory response during and after coronary artery surgery [19] and decreased mortality in critically ill patients, most after elective cardiac procedure [20]. Observational studies further suggest that the quality of glycemic control affects morbidity and mortality in diabetic patients undergoing coronary artery bypass grafting [21]. Hence, perioperative maintenance of normoglycemia gains clinical relevance.

In the present protocol, epidural analgesia limited the hyperglycemic and cortisol responses to OPCAB whether fentanyl or clonidine was added to epidural bupivacaine or not. This finding is in agreement with previous observations reporting inhibitory effects of TEA on the metabolicendocrine responses to cardiac [22-24] and non-cardiac surgery [25]. Studies using stable isotope tracer kinetics during MIDCAB and abdominal surgery showed that thoracic epidural analgesia attenuates the perioperative increase in blood glucose through the inhibition of endogenous glucose production rather than through an increase in glucose utilization $[23,26]$.

There is controversy about the role of TEA in preventing the inflammatory response during cardiac surgery.

Some studies conducted in patients undergoing on-pump coronary artery bypass grafting did not demonstrate a modi- fying influence of TEA on cytokine production [27] and the circulating cortisol and catecholamine concentrations [28]. Fransen et al. [29] investigated in a small number of patients the influence of cardiopulmonary bypass on the systemic inflammation. The release of bactericidal permeability increasing protein was markedly reduced during OPCAB, thus indicating a decreased response of the polymorphonuclear neutrophil protein with possible benefits for outcome after cardiac surgery. Two other studies have also found a reduction in cytokine response during $\mathrm{OPCAB}[30]$ and tumor necrosis factor [31]. However, the acute phase response as indicated by interleukin- 6 release was the same for OPCAB and $\mathrm{OnCAB}$, indicating that surgery as such is the drive behind the acute inflammatory response. As much as for OnCAB, TEA reduces cortisol and catecholamine release during surgery in OPCAB [25].

\section{Clonidine in Epidural Administration}

Clonidine is a $\alpha 2$-adrenergic agonist with analgesic properties and the propensity to potentiate the effects of local anesthetics [32,33]. Concern has been described about the possible effect of clonidine addition in epidural infusions because of the possible effect on the blood pressure. Whereas one recent study [34] showed lower blood pressure when clonidine was added to ropivacaine for epidural analgesia after spinal anesthesia, we could not support these findings in a previous study with the same study setup [35, 36] Although this was not the main focus of the study, perioperative blood pressure and heart rate remained stable and was not different between the three groups.

Very little is known whether the addition of clonidine to a local anesthetic in epidural analgesia improves the stress 


\section{Cortisol Levels}

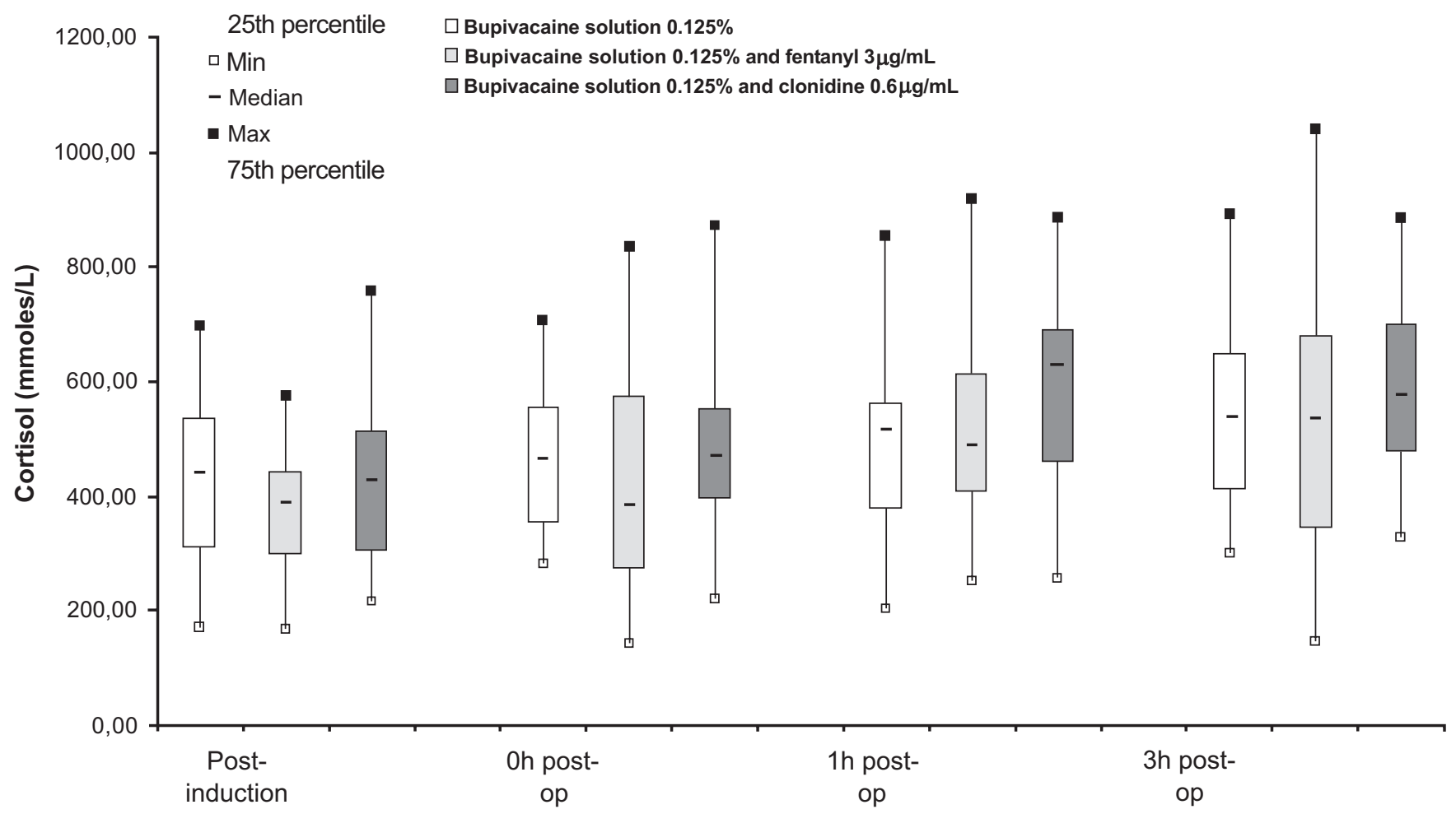

Fig. (2). Cortisol levels immediately after intubation, immediately after extubation and $1 \mathrm{~h}$ and $3 \mathrm{~h}$ after surgery.

response [32]. However, some studies in children showed an increase in postoperative sedation when clonidine was added to caudal blockade [37-39]. We did not find any such influence in our study.

\section{Fentanyl as Adjunct to Epidural Analgesia}

The fact that sole bupivacaine produced already very good pain scores, might be one of the reasons why the addition of clonidine or fentanyl did not further improve stress protection. Only few studies have shown a beneficial effect of adding fentanyl to an epidural of local anesthetic. The results of a recent study performed in patients undergoing colorectal procedures lend support to the assumption that local anesthetic and opioid must be administered concomitantly to suppress the catabolic responses to surgery [40].

Furthermore Breslow et al [41] have shown a diminution of the inflammatory response in surgery of the lower extremities when bupivacaine and fentanyl were used as an epidural solution. However, in that study, no control group with solely bupivacaine was compared. Other studies in adults did not show any adding effect in terms of stress protection with opioids in adults [42,43], nor in children [44]. This is in concordance with our findings. Possibly, the excellent pain control is the confounding factor in optimal stress control.

\section{Epidural Hematoma in OPCAB}

The risks of epidural hematoma has been calculated as being lower than 1:1500 in OnCAB [45]. This calculation was not made for OPCAB, but since the heparinization is less in off-pump surgery, the risk should be lower. The lower doses of heparin used in OPCAB (150 IU $/ \mathrm{kg})$ are similar to doses used in vascular surgery where the use of TEA is well established. When calculating the risks, we must considerate the possibility of converting an off-pump surgery to an onpump CABG. In our institution, nearly $95 \%$ of coronary bypass are done off-pump with a very low conversion rate $(<$ $2 \%$ ) to on-pump surgery. The risk of a hematoma should be significantly lower than 1: 1500 .

In conclusion, this study showed that TEA for beating heart surgery prevented raise in cortisol reflecting a perioperative hormonal stress protection. The addition of either fentanyl $3 \mu \mathrm{g} / \mathrm{ml}$ or clonidine $0,06 \%$ to bupivacaine $0,125 \%$ did not further improve that stress protection.

\section{REFERENCES}

[1] Liu S, Carpenter RL, Neal JM. Epidural anesthesia and analgesia. Their role in postoperative outcome. Anesthesiology 1995; 82: 1474-506.

[2] Stenseth R, Bjella L, Berg EM, Christensen O, Levang OW, Gisvold SE. Thoracic epidural analgesia in aortocoronary bypass surgery. I: Haemodynamic effects. Acta Anaesthesiol Scand 1994; 38: 826-33.

[3] Hemmerling TM, Choiniere JL, Basile F, Le N, Olivier JF, Prieto I. Immediate extubation after aortic valve surgery using high thoracic epidural anesthesia. Heart Surg Forum 2004; 7: 16-20.

[4] Joachimsson PO, Nystrom SO, Tyden H. Early extubation after coronary artery surgery in efficiently rewarmed patients: a postoperative comparison of opioid anesthesia versus inhalational anesthesia and thoracic epidural analgesia. J Cardiothorac Anesth 1989; 3: 444-54. 
[5] Hemmerling TM, Prieto I, Choiniere JL, Basile F, Fortier JD. Ultra-fast-track anesthesia in off-pump coronary artery bypass grafting. a prospective audit comparing opioid-based anesthesia $v s$ thoracic epidural-based anesthesia. Can J Anaesth 2004; 51: 163-8.

[6] Scott NB, Turfrey DJ, Ray DA, et al. A prospective randomized study of the potential benefits of thoracic epidural anesthesia and analgesia in patients undergoing coronary artery bypass grafting. Anesth Analg 2001; 93: 528-35.

[7] Schricker T, Klubien K, Carli F. The independent effect of propofol anesthesia on whole body protein metabolism in humans. Anesthesiology 1999; 90: 1636-42.

[8] Schricker T, Klubien K, Wykes L, Carli F. Effect of epidural blockade on protein, glucose, and lipid metabolism in the fasted state and during dextrose infusion in volunteers. Anesthesiology 2000; 92: 62-9.

[9] Schricker T, Wykes L, Carli F. Epidural blockade improves substrate utilization after surgery. Am J Physiol Endocrinol Metab 2000; 279: E646-53.

[10] Carli F, Schricker T. Modulation of the catabolic response to surgery. Nutrition 2000; 16: 777-80.

[11] Tonnesen E, Brinklov MM, Christensen NJ, Olesen AS, Madsen T. Natural killer cell activity and lymphocyte function during and after coronary artery bypass grafting in relation to the endocrine stress response. Anesthesiology 1987; 67: 526-33.

[12] Menasche P. The inflammatory response to cardiopulmonary bypass and its impact on postoperative myocardial function. Curr Opin Cardiol 1995; 10: 597-604.

[13] Casey LC. Role of cytokines in the pathogenesis of cardiopulmonary-induced multisystem organ failure. Ann Thorac Surg 1993; 56: S92-6.

[14] McBride WT, Armstrong MA, Crockard AD, McMurray TJ, Rea JM. Cytokine balance and immunosuppressive changes at cardiac surgery. contrasting response between patients and isolated $\mathrm{CPB}$ circuits. Br J Anaesth 1995; 75: 724-33.

[15] Chaney MA, Nikolov MP, Blakeman BP, Bakhos M. Attempting to maintain normoglycemia during cardiopulmonary bypass with insulin may initiate postoperative hypoglycemia. Anesth Analg 1999; 89: 1091-5.

[16] Carvalho G, Moore A, Qizilbash B, Lachapelle K, Schricker T. Maintenance of normoglycemia during cardiac surgery. Anesth Analg 2004; 99: 319-24, (Table of Contents).

[17] Carvalho G, Schricker T. An ounce of prevention worth a pound of cure. Can J Anaesth 2004; 51: 948-9.

[18] McAlister FA, Man J, Bistritz L, Amad H, Tandon P. Diabetes and coronary artery bypass surgery. an examination of perioperative glycemic control and outcomes. Diabetes Care 2003; 26: 1518-24.

[19] Visser L, Zuurbier CJ, Hoek FJ, et al. Glucose, insulin and potassium applied as perioperative hyperinsulinaemic normoglycaemic clamp. effects on inflammatory response during coronary artery surgery. Br J Anaesth 2005; 95: 448-57.

[20] van den Berghe G, Wouters P, Weekers F, et al. Intensive insulin therapy in the critically ill patients. N Engl J Med 2001; 345: 135967

[21] Furnary AP, Gao G, Grunkemeier GL, et al. Continuous insulin infusion reduces mortality in patients with diabetes undergoing coronary artery bypass grafting. J Thorac Cardiovasc Surg 2003; 125: 1007-21.

[22] Ganapathy S, Murkin JM, Dobkowski W, Boyd D. Stress and inflammatory response after beating heart surgery versus conventional bypass surgery. the role of thoracic epidural anesthesia. Heart Surg Forum 2001; 4: 323-7.

[23] Ganapathy S. Thoracic epidural analgesia (TEA) inhibits intraoperative glucose production in minimally invasive coronary artery bypass surgery (MIDCAB). Can cardiovasc soc 2000; 195.
[24] Moore CM, Cross MH, Desborough JP, Burrin JM, Macdonald IA, Hall GM. Hormonal effects of thoracic extradural analgesia for cardiac surgery. Br J Anaesth 1995; 75: 387-93.

[25] Ganapathy S, Murkin JM, Boyd DW, Dobkowski W, Morgan J. Continuous percutaneous paravertebral block for minimally invasive cardiac surgery. J Cardiothorac Vasc Anesth 1999; 13: 594-6.

[26] Lattermann R, Carli F, Wykes L, Schricker T. Epidural blockade modifies perioperative glucose production without affecting protein catabolism. Anesthesiology 2002; 97: 374-81.

[27] Brix-Christensen V, Tonnesen E, Sorensen IJ, Bilfinger TV, Sanchez RG, Stefano GB. Effects of anaesthesia based on high versus low doses of opioids on the cytokine and acute-phase protein responses in patients undergoing cardiac surgery. Acta Anaesthesiol Scand 1998; 42: 63-70.

[28] Roth-Isigkeit A, Brechmann J, Dibbelt L, Sievers HH, Raasch W, Schmucker P. Persistent endocrine stress response in patients undergoing cardiac surgery. J Endocrinol Invest 1998; 21: 12-9.

[29] Fransen E, Maessen J, Dentener M, Senden N, Geskes G, Buurman W. Systemic inflammation present in patients undergoing CABG without extracorporeal circulation. Chest 1998; 113: 1290-5.

[30] Wan S, Izzat MB, Lee TW, Wan IY, Tang NL, Yim AP. Avoiding cardiopulmonary bypass in multivessel CABG reduces cytokine response and myocardial injury. Ann Thorac Surg 1999; 68: 52-6; discussion 56-7.

[31] Brasil LA, Gomes WJ, Salomao R, Buffolo E. Inflammatory response after myocardial revascularization with or without cardiopulmonary bypass. Ann Thorac Surg 1998; 66: 56-9.

[32] Eisenach JC, De Kock M, Klimscha W. Alpha(2)-adrenergic agonists for regional anesthesia. A clinical review of clonidine (1984-1995). Anesthesiology 1996; 85: 655-74.

[33] Milligan KR, Convery PN, Weir P, Quinn P, Connolly D. The efficacy and safety of epidural infusions of levobupivacaine with and without clonidine for postoperative pain relief in patients undergoing total hip replacement. Anesth Analg 2000; 91: 393-7.

[34] Dobrydnjov I, Axelsson K, Gupta A, Lundin A, Holmstrom B, Granath B. Improved analgesia with clonidine when added to local anesthetic during combined spinal-epidural anesthesia for hip arthroplasty. a double-blind, randomized and placebo-controlled study. Acta Anaesthesiol Scand 2005; 49: 538-45.

[35] Olivier JF, Le N, Choiniere JL, Prieto I, Basile F, Hemmerling T. Comparison of three different epidural solutions in off-pump cardiac surgery. pilot study. Br J Anaesth 2005; 95: 685-91.

[36] Olivier JF, Hemmerling TM. Comparison of three different epidural solutions in cardiac surgery : a pilot study. Br J Anaesth 2005; 95(5): 685-91.

[37] Klimscha W, Chiari A, Michalek-Sauberer A, et al. The efficacy and safety of a clonidine/bupivacaine combination in caudal blockade for pediatric hernia repair. Anesth Analg 1998; 86: 54-61.

[38] Motsch J, Bottiger BW, Bach A, Bohrer H, Skoberne T, Martin E. Caudal clonidine and bupivacaine for combined epidural and general anaesthesia in children. Acta Anaesthesiol Scand 1997; 41: 877-83.

[39] Ivani G, Mattioli G, Rega M, Conio A, Jasonni V, de Negri P. Clonidine-mepivacaine mixture $v s$ plain mepivacaine in paediatric surgery. Paediatr Anaesth 1996; 6: 111-4.

[40] Schricker T, Wykes L, Eberhart L, Lattermann R, Carli F. Epidural ropivacaine versus epidural morphine and the catabolic response to colonic surgery. stable isotope kinetic studies in the fasted state and during infusion of glucose. Anesthesiology 2004; 100: 973-8.

[41] Breslow MJ, Parker SD, Frank SM, et al. Determinants of catecholamine and cortisol responses to lower extremity revascularization. The PIRAT Study Group. Anesthesiology 1993; 79: 1202-9.

[42] Normandale JP, Schmulian C, Paterson JL, Burrin J, Morgan M, Hall GM. Epidural diamorphine and the metabolic response to upper abdominal surgery. Anaesthesia 1985; 40: 748-53. 
[43] Rutberg H, Hakanson E, Anderberg B, Jorfeldt L, Martensson J, Schildt B. Effects of the extradural administration of morphine, or bupivacaine, on the endocrine response to upper abdominal surgery. Br J Anaesth 1984; 56: 233-8.

[44] Gaitini LA, Somri M, Vaida SJ, et al. Does the addition of fentanyl to bupivacaine in caudal epidural block have an effect on the plasma level of catecholamines in children? Anesth Analg 2000; 90: 1029-33.

[45] Ho AM, Chung DC, Joynt GM. Neuraxial blockade and hematoma in cardiac surgery. estimating the risk of a rare adverse event that has not (yet) occurred. Chest 2000; 117: 551-5.

(C) Olivier et al.; Licensee Bentham Open.

This is an open access article licensed under the terms of the Creative Commons Attribution Non-Commercial License (http: //creativecommons.org/licenses/by-nc/ $3.0 /$ ) which permits unrestricted, non-commercial use, distribution and reproduction in any medium, provided the work is properly cited 